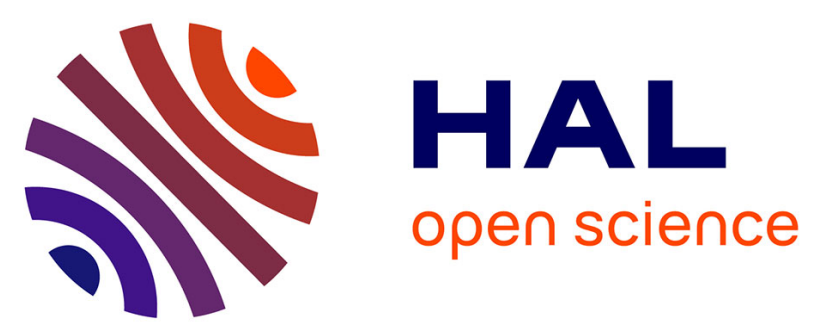

\title{
SYSIPHE, an airborne hyperspectral system from visible to thermal infrared
}

L. Rousset-Rouvière, I. Sisakoun, T. Skauli, C. Coudrain, Y. Ferrec, S. Fabre, L. Poutier, Y. Boucher, T. Loke, S. Blaaberg

\section{- To cite this version:}

L. Rousset-Rouvière, I. Sisakoun, T. Skauli, C. Coudrain, Y. Ferrec, et al.. SYSIPHE, an airborne hyperspectral system from visible to thermal infrared. 2016 IEEE International Geoscience and Remote Sensing Symposium (IGARSS 2016), Jul 2016, Pékin, China. hal-01386543

\section{HAL Id: hal-01386543 https://hal.science/hal-01386543}

Submitted on 26 Oct 2016

HAL is a multi-disciplinary open access archive for the deposit and dissemination of scientific research documents, whether they are published or not. The documents may come from teaching and research institutions in France or abroad, or from public or private research centers.
L'archive ouverte pluridisciplinaire HAL, est destinée au dépôt et à la diffusion de documents scientifiques de niveau recherche, publiés ou non, émanant des établissements d'enseignement et de recherche français ou étrangers, des laboratoires publics ou privés. 


COMMUNICATION A CONGRES
SYSIPHE, an airborne hyperspectral
system from visible to thermal
infrared

L. Rousset-Rouviere, I. Sisakoun (DGA),
T. Skauli (FFI), C. Coudrain, Y. Ferrec, S. Fabre,
L. Poutier, Y. Boucher, T. Løke (NEO AS),
S. Blaaberg (NEO AS)


IGARSS 2016
BEIJING, CHINE
10-15 juillet 2016
TP 2016-562

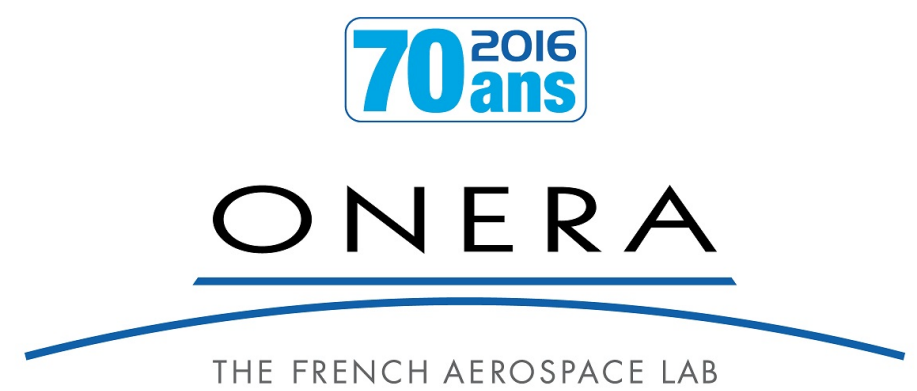





\title{
SYSIPHE, AN AIRBORNE HYPERSPECTRAL SYSTEM FROM VISIBLE TO THERMAL INFRARED
}

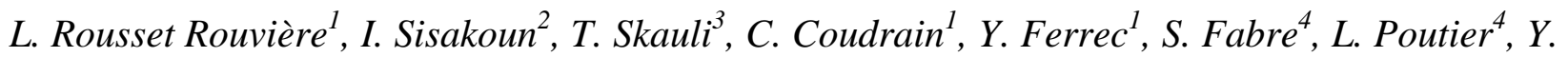 \\ Boucher $^{4}$, T. L $\phi k e^{5}$, S. Blaaberg 5
}

(1) ONERA, centre de Palaiseau, chemin de la Hunière, 91761 Palaiseau cedex, France (2) DGA, - 60 Bd du Général Martial Valin 75509 Paris cedex 15 - France

(3) FFI, P O Box 25, 2027 Kjeller, Norway

(4) ONERA, centre de Toulouse, 2 avenue Edouard Belin, BP 74025, 31055 Toulouse cedex 4, France

(5) Norsk Elektro Optikk AS, Prost Stabels vei 22, N-2019 Skedsmokorset Norway

\begin{abstract}
SYSIPHE is an airborne hyperspectral imaging system covering all atmospheric transmission bands from $0.4 \mu \mathrm{m}$ to 11.5 $\mu \mathrm{m}$ : visible, NIR, SWIR, MWIR and LWIR. The ground sampling distance is $0.5 \mathrm{~m}$ over a $500 \mathrm{~m}$ swath, with higher resolution available in the visible and NIR. The imaging system, developed by Onera and Norsk Elektro Optikk, is flown on a Do-228 aircraft operated by DLR. The SYSIPHE system may also integrate a real-time processing capability developed by FFI and a ground post-processing chain, the STAD, developed by Onera. The main information products are georeferenced images of spectral radiance, spectral emissivity and reflectance as well as a surface temperature map. The system has completed its first flight campaign successfully in 2013. A qualification campaign for Defence needs was done during the summer 2015. SYSIPHE represents a significant enhancement of airborne sensing capabilities in Europe. The system will be made available soon to external users.
\end{abstract}

Index Terms - hyperspectral, infrared, remote sensing

\section{MOTIVATION AND OBJECTIVES}

The general objective of the SYSIPHE system is to validate and quantify the interest of spectral imaging techniques for defence, security and environmental applications. The SYSIPHE system will supply hyperspectral data that may be used in studies related to a variety of scenarios represented by ground scenes, even in real time.

SYSIPHE requirements are based on both civilian and military applications. It can address a huge variety of applications like improved target/background separation or classification (including counter camouflage or target decoy), soil characterization and classification, vegetation studies, gas or chemical agent detection, bathymetry, hydrography and so on.

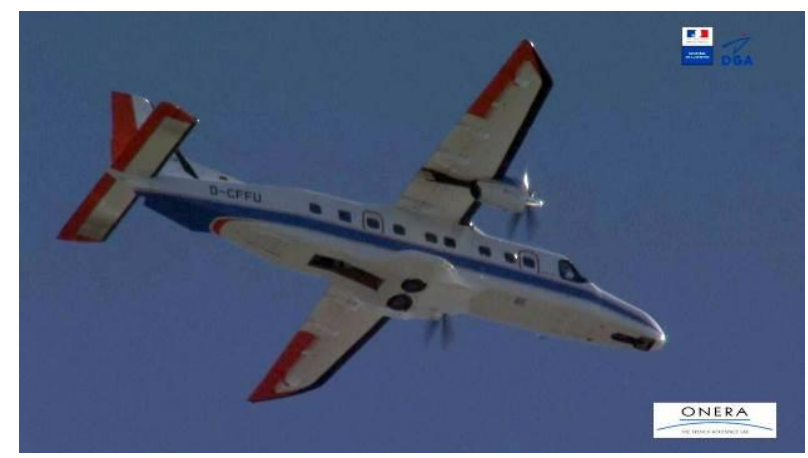

Figure 1: The Do-228 with the hatch opened

SYSIPHE is characterised by its unique spectral coverage from 0.4 to $11.8 \mu \mathrm{m}$ in the atmospheric transmission bands. This spectral coverage was the main driver for the implementation of three hyperspectral cameras into the same aircraft to provide spatially and temporally coherent measurements over the whole spectral domain. The pre-processing inherent to each instrument will lead to georeferenced and inter-band registered radiance data. In addition, a real-time pre-processing system could be used to demonstrate or to explore concepts of operation.

\section{SYSIPHE SYSTEM}

The SYSIPHE system was built in collaboration between France and Norway. It is unique by its wide spectral coverage, combined with a high spatial resolution $(0.5 \mathrm{~m}$ ground sampling distance over a 500m swath).

To achieve this performance, SYSIPHE is composed of three instruments: HySpex Odin 1024, for the visible, NIR and SWIR ranges, developed by Norsk Elektro Optikk in Norway (NEO), and Sieleters-MWIR and -LWIR, developed by the French aerospace laboratory Onera. These three instruments are integrated on the same aircraft, a Do228 operated by the German aerospace center DLR (see Figure 1). By having imagers for all bands in the same 
aircraft, SYSIPHE can produce georeferenced images of spectral radiance with more than 560 spectral bands.

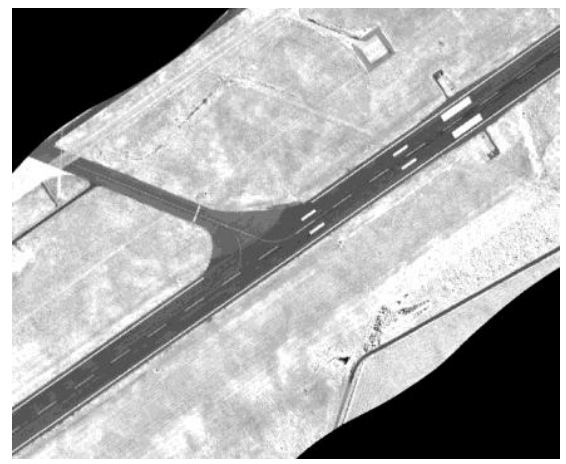

Figure 2: Monochromatic (1134nm) georectified image acquired by HySpex Odin-1024

The SYSIPHE system may also integrate a real-time processing capability dedicated for target detection (developed by FFI) [1], and a ground pre-processing chain, the STAD, developed by Onera to register the hyperspectral images of each instrument and to produce georeferenced outputs as spectral radiance, ground spectral reflectance, and surface temperature maps.

\section{ODIN INSTRUMENT}

HySpex Odin 1024 [2] is the visible and shortwave infrared part of the SYSIPHE project. It was developed by NEO. It consists of two push broom imaging spectrographs based on transmissive gratings. These two modules share a common fore-optics and a common slit, to ensure perfect registration between the VNIR and the SWIR images. The spectral resolution varies from $5 \mathrm{~nm}$ the visible to $6 \mathrm{~nm}$ in the shortwave infrared.

The HySpex Odin-1024 has an onboard spectral and radiometric calibration source. The VNIR channel is capable of higher spatial/spectral resolution than the other SYSIPHE bands by sampling 2560 cross-track pixels. Figure 2 shows a single spectral channel of a georectified airborne hyperspectral image acquired by HySpex Odin-1024. Figure 6 shows an Odin image for the spectral channel at $1334 \mathrm{~nm}$.

\section{SIELETERS INSTRUMENT}

Sieleters is the infrared component of SYSIPHE. It is composed of two distinct instruments, one for the midwave infrared domain $([3 \mu \mathrm{m} ; 5.4 \mu \mathrm{m}])$ and one for the longwave infrared domain $([8 \mu \mathrm{m} ; 11.8 \mu \mathrm{m}])$. The spectral resolution is $11 \mathrm{~cm}^{-1}$ in the MWIR and $5 \mathrm{~cm}^{-1}$ in the LWIR. Both instruments are cryogenic to achieve high performance absolute measurements, and both are imaging static Fourier transform spectrometers [4]. Figure 3 shows a Sieleters image for the spectral channel at $4.8 \mu \mathrm{m}$.

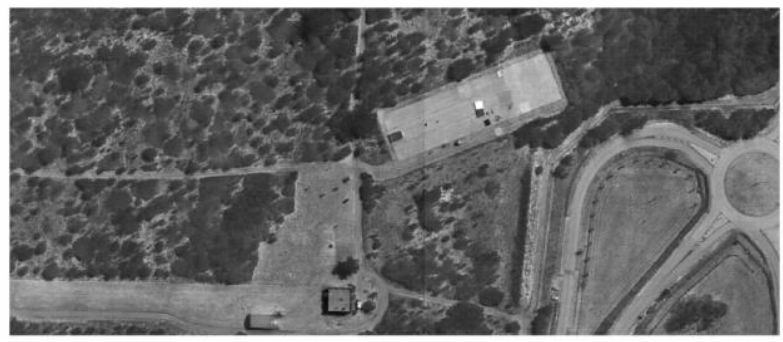

Figure 3: Monochromatic (4.8 $\mu \mathrm{m})$ image acquired by Sieleters-MWIR

\section{SYSIPHE FLIGHT ACCEPTANCE CAMPAIGN}

A flight campaign was led in September, 2013, on the French air base of Cazaux. This site was chosen because the DGA-EV (French military flight test center) has a large active infrared target which allows to measure in-flight radiometric and imaging performances of airborne infrared systems. The Cobra target is composed with independent panels to create controlled temperature patterns.

Most of parameters of Odin and Sieleters instruments were measured during this campaign (details for Sieleters can be found in [3]). Table 1 gives a summary of the principle characteristics of the instruments.

\begin{tabular}{|c|c|c|}
\hline ODIN & & \\
\hline Parameter & VNIR & SWIR \\
\hline Spectral range $(\mu \mathrm{m})$ & $0.40-1.00$ & $0.95-2.50$ \\
\hline Spectral resolution $(\mathrm{nm})$ & 5.0 & 6.1 \\
\hline Pixel FOV (mrad) & 0.25 & 0.25 \\
\hline Total across track FOV & $15^{\circ}$ & $15^{\circ}$ \\
\hline F-number & F1.5 & $\mathrm{F} 2.0$ \\
\hline \multicolumn{3}{|l|}{ SIELETERS } \\
\hline Parameter & MWIR & LWIR \\
\hline Spectral range $(\mu \mathrm{m})$ & $3.0-5.4^{*}$ & $8.1-11.8 *$ \\
\hline Spectral resolution $\left(\mathrm{cm}^{-1}\right)$ & 11 & 5 \\
\hline Pixel FOV (mrad) & 0.25 & 0.25 \\
\hline Total across track FOV & $15^{\circ}$ & $15^{\circ}$ \\
\hline F-number & $\mathrm{F} 4.0$ & F3.0 \\
\hline $\operatorname{NESR}\left(\mathrm{ph} / \mathrm{s} / \mathrm{m} 2 / \mathrm{sr} / \mathrm{m}^{-1}\right)$ & $3.010^{13 *}$ & $7.510^{14 \dagger}$ \\
\hline
\end{tabular}

Table 1: Main technical specifications for Odin and Sieleters (values are subject to change due to on-going development)

The spectra of three individual pixels are drawn on Figure 4 and Figure 5. They correspond to a pixel lying inside a large polystyrene target which was set on the ground (green curve), to a pixel lying on a white target (blue curve), and to a pixel lying on a dark target (red curve). 


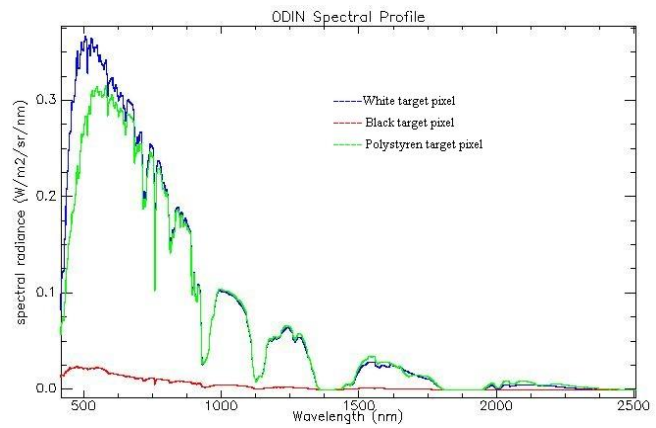

Figure 4: ODIN spectra of 3 individual pixels, respectively placed in the polystyren target (green), the white target (blue) and the black target (red).

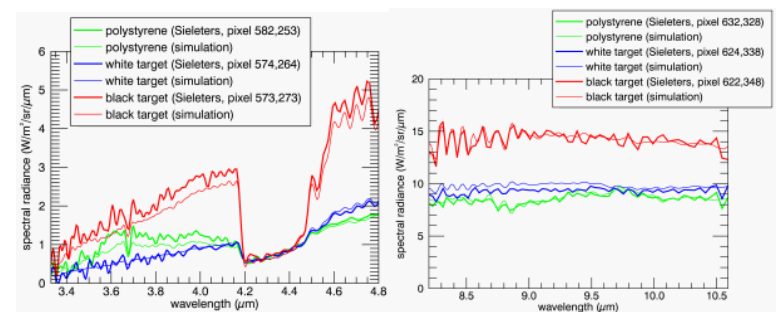

Figure 5: Sieleters spectra of 3 individual pixels, respectively placed in the polystyrene target (green), the white target (blue) and the dark target (red) compared to the ground spectral radiance measure propagated to the pupil of the Sieleters instrument

For Figure 5, the bold curves are the spectra from Sieleters measurements, the normal curves are the ground truth measurement propagated to the entrance window of the instrument Sieleters using Comanche code [4]. From these spectra, it appears that the signal to noise ratio has still to be improved. Various avenues are currently explored to enhance the SNR. Nevertheless, these spectra show a good agreement in terms of both spectral and radiometric calibration. The Odin spectra couldn't be compared to ground truth measurement due to the cloudy sky. In this atmospheric condition, the ground measurements are not validated.

\section{SYSIPHE 2015 CAMPAIGN}

The data acquired during the 2013 airborne campaign couldn't address all the verification needed to qualify the SYSIPHE system, especially the verification of the calibration of the instruments and the atmospheric correction software used in the STAD. For this reason, a new airborne campaign was scheduled in August 2015 where measurements with clean sky were done.

This campaign was located in the South of France, in the military base of Canjuers. A ground truth workshop was deployed covering different targets (Figure 6). In parallel, military scenarios were deployed in the Canjuers base to acquire full bandwidth hyperspectral images with SYSIPHE.

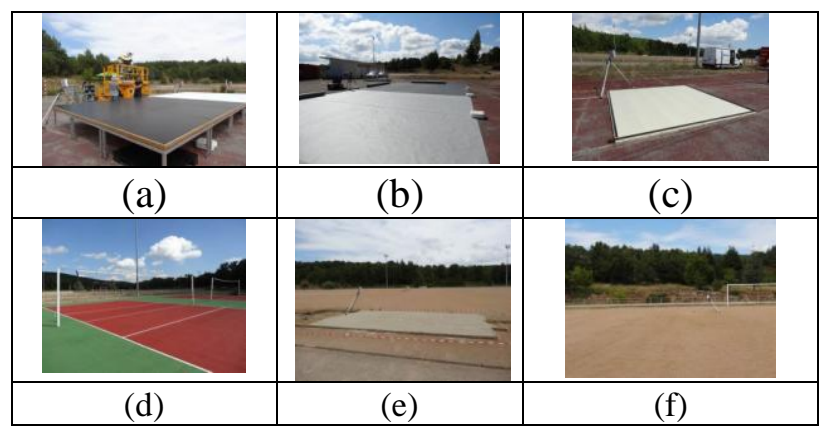

Figure 6: Targets and reference ground surface for ground truth measurements. (a) black and white panels, (b) linoleum panels, (c) polystyrene panel, (d) painted concrete, (e) sand, (f) clay.

The campaign was led from 17th of August to 2nd of September 2015. During this campaign, the system flew 7 times including a night flight. Different meteorological conditions were encountered: clean sky, partially cloudy, windy, opening new studies on the robustness of hyperspectral products in function of the weather conditions.

\section{CONCLUSION}

SYSIPHE is now at the end of its initial development phase. The flight acquisition was performed with a large success demonstrating the operability of the spectro-imagers for airborne campaign. Laboratory and in-flight measurements are in accordance with the expected performances. Hyperspectral airborne images acquired during the qualification 2015 campaign are currently being processed.

The SYSIPHE system will be proposed soon to external users for military or scientific/civilian purposes, with an ability to offer turnkeys campaigns with a wide range of support options, including organization of airborne campaigns and data processing.

\section{REFERENCES}

[1] T. Skauli, T. V. Haavardsholm, I. Kåsen, G. Arisholm, A. Kavara, T. O. Opsahl, and A. Skaugen, "An airborne real-time hyperspectral target detection system," Proc. SPIE 7695, 76950A (2010)

[2] T. Loke and al., "A next generation VNIR-SWIR hyperspectral camera system : HySpex ODIN-1024,” Proc. SPIE 9249, 9249-32 (2014)

[3] C. Coudrain and al., "SIELETERS, an airborne infrared dualband spectro-imaging system for measurement of scene spectral signatures," Optics Express vol. 23 n¹2 pp. 16164-16176 (2015)

[4] L. Poutier and al., "COMANCHE and COCHISE : two reciprocal atmospheric codes for hyperspectral remote sensing," Proc. of 2002 AVIRIS Earth Science and Applications Workshop (2002) 
Office National d'Études et de Recherches Aérospatiales Chemin de la Hunière et des Joncherettes - BP 80100 91123 PALAISEAU Cedex

Tél. : +33180386060-Fax : +33180386510 http://www.onera.fr 